\title{
Pengaruh Latihan Splite Terhadap Ketepatan Sasaran Sepak Service dalam Permainan Sepak Takraw pada Team Regu Putra UNDIKMA Mataram 2020
}

\author{
Herman Syah ${ }^{1}$ \\ ${ }^{1}$ Dosen Universitas Pendidikan Mandalika \\ hermansyahikipmataram@gmail.com
}

\begin{abstract}
Abstrak, Sepak takraw merupakan olahraga yang selalu dipertandingkan dalam setiap kejuaraan baik daerah, nasional maupun internasional. Untuk mendapat prestasi dalam permainan sepak takraw, ada beberapa faktor yang mempengaruhiny, salah satu faktor yang dimaksud adalah latihan pleksibilitas, daya ledak, kordinasi, latihan yang kontinyu serta penguasaan tehnik yang baik. Yang ada kaitannya dengan penelitian ini bahwa salah satu faktor yang mempengaruhi prestasi sepak service dalam permainan sepak takraw adalah latihan splite dengan asumsi bahwa semakin sering melakukan latihan splite maka otot-otot kaki semakin besar, kuat dan lentur sehingga besar peluang untuk mendapatkan sepakkan yang tepat sesuai dengan tujuan yang diinginkan. Dimana didalam penelitian ini menggunakan metode penelitian atau cara melakukan penelitian adalah aksprimen. karena harus menggumpulkan dari hasil pengukuran sebelum dan sesudah melakukan latihan splite terhadap ketepatan sasaran sepak service /sepak mula. Dan yang menjadi rancangan penelitian mengunakan penelitian eksprimen sungguhan "One group" Pre-tes dan Pos-test. Setelah mendapatkan nilai t-hitung (to) lebih besar dari pada nilai t-tabel (tt) dengan taraf signifikan 5\% maka dengan dasar ini dapat mennolak suatu hipotesis nihil (Ho). Jadi hipotesis yang digunakan dalam penelitian ini adalah hipotesis alternatif (Ha). Berdasarkan kenyataan diatas yaitu nilai t-tabel dengan demikian nilai t yang diperoleh dalam penelitian ini adalah signifikan. Kesimpulan " Ada Pengaruh Sebelum Atlet Melakukan Latihan Splite Dengan Setelah Melakukan Latihan Splite Terhadap Ketepatan Sasaran Sepak Service Dalam Permainan Sepak Takraw Pada Team Regu Putra UNDIKMA Mataram tahun 2020".
\end{abstract}

Kata-kata Kunci : Pengaruh Latihan Splite, Ketepatan Sasaran Sepak Service, Permainan Sepak Takraw.

\begin{abstract}
Sepak takraw is a sport that is always contested in every championship both regional, national and international. To get an achievement in the soccer game takraw, there are several factors that influence $i$, one of the factors in question is training flexibility, explosive power, coordination, continuous training and mastery of good techniques. Which has to do with this research that one of the factors that influence the performance of soccer service in the game takraw is splite training with the assumption that the more frequent splite exercises the leg muscles are getting bigger, stronger and more flexible so there is a greater chance of getting the right soccer according with the desired goal. Where in this study using research methods or how to conduct research is expression. because they have to collect from the measurement results before and after doing splite training on the accuracy of soccer service / soccer targets. And the research design uses real "One group" pre-test and post-test experimental research. After getting the value of t-count (to) is greater than the value of $t$-table (tt) with a significant level of $5 \%$ then on this basis can reject a null hypothesis (Ho). So the hypothesis used in this study is an alternative hypothesis (Ha). Based on the fact above, the t-table value is thus the $t$ value obtained in this study is significant. Conclusion "There Is Influence Before Athletes Do Splite Training With After Doing Splite Training Against the Accuracy of Football Service Targets in Takraw Football Game on the UNDIKMA Men's Mataram Team in 2020".
\end{abstract}

Key Words: Effects of Splite Training, Accuracy in Football Service Target, Sepak Takraw Games.

\section{PENDAHULUAN}

Sepak takraw merupakan cabang olahraga permainan asli Indonesia. Permainan ini dilakukan oleh dua regu yang berlawanan, setiap regu terdiri dari 3 orang pemain, yang dipisahkan oleh sebuah net yang memiliki ukuran dan ketinggian sama dengan bulu tangkis, yaitu 1,44 meter. Permainan ini dimulai dengan melakukan servis, yang dilakukan oleh tekong ke daerah lapangan lawan.Kemudian pemain regu lawan mencoba memainkan bola dengan menggunakan kaki, kepala dan anggota badan selain tangan, sebanyak 3 kali sentuhan. 
Menurut Sofyan (2009:2), sepak takraw adalah jenis olahraga campuran dari sepak bola dan bola volley, dimainkan dilapangan ganda badminton dan pemain tidak boleh menentuh bola dengan tangan. Permainan sepak takraw yang dimainkan sekarang ini adalah permainkan yang menggunakan bola yang terbuat dari rotan dan plastik (synthetic fibre). Bola ditendang dari kaki ke kaki, memberi umpan kepada kawan dan memukul atau mematikan bola dilapangan lawan (Yusup. 2001:3).

Menurut Yusup (2001:30), teknik dasar dalam permainan sepak takraw antara lain sepakan, heading, mendada, servis, smash, bloking. Hal ini disebabkan oleh beberapa faktor, salah satu diantaranya adalah foktor latihan yaitu latihan split.

Latihan split merupakan latihan memiliki pengaruh yang sangat besar dalam melakukan sepak servis agar mendapatkan hasil yang maksimal dan memuaskan. Adapun macam-macam latihan split yang dilakukan antara lain sebagai berikut: (a) Split samping dilantai, (b) Split depan dilantai, (c) Split dengan dibantu oleh teman.

Splite adalah gerakan menarik kedua kaki kekiri dan kekanan atau kedepan dan kebelakang dengan posisi badan bagian atas berada diantara kedua kaki yang terbuka (Sumarjono. 2001). Gerakan splite ini merupakan perenggangan kangkang (untuk paha belakang, paha dalam dan pinggang).

Ketepatan berasal dari kata tepat yang artinya kena benar pada sasaran, sedangkan ketepatan yang artinya ketelitian atau kejituan (Moeliono, 1993). Sedangkan sasaran menurut kamus besar bahasa Indonesia (BBI) adalah suatu yang menjadi tujuan (Moeliono, 1993). Dari kedua pendapat tersebut diatas yang dimaksud dengan ketepatan sasaran adalah kejituan atau ketepatan sasaran terhadap suatu yang menjadi tujuan.

Dari hasil latihan split yang dilakukan diatas dapat membuat, merangsang otot kaki (tungkai) menjadi lentur. Semakin lentur otot kaki (tungkai) pemain dalam melakukan latihan split semakin maksimal pula hasil sepak servis yang dihasilkan oleh para atlet (pemain) sepak takraw terutama pada posisi tekong.

\section{METODE PENELITIAN}

Dalam buku metodologi penelian dijelaskan bahwa "Rancangan dasarnya merupakan keseluruhan proses pemikiran dan penentuan matang tentang hal-hal yang serta dapat pula di jadikan dasar penelitian baik oleh peneliti itu sendiri maupun orang lain terhadap penelitian, dan bertujuan memberi pertanggung jawaban terhadap semua langkah yang diambil" (Margono, $2004: 100$ ).

Dalam penelitian ini yang menjadi variable terikat (dependen) adalah ketepan sasaran sepak servis, dan yang menjadi variable bebas (independent) adalah splite. Yang ditinjau dari penelitian ini adalah ketercapaian indiKator pada variable terikat atau ketepatan sasaran sepak servis.

Adapun populasi dalam penelitian ini adalah team regu putra sepak takraw UNDIKMA Mataram berjumlah 12 orang.

Sedangkan sampel dalam penelitian ini peneliti tidak menggunakan sample, bahwa populasi yang terdapat dalam penelitian berjumlah 12 orang. Sehingga peneliti menggunakan study populasi karna semua populasi diikut sertakan dalam penelitian ini.

Instrumen yang digunakan untuk memperoleh data-data penelitian ini adalah instrument tes, yaitu tes servis. Adapun beberapa hal yang perlu di perhatikan dalam melakukan tes servis ini antara lain sebagai berikut:

1. Saat tester mengatakan siap, tester berdiri siap melakukan melakukan servis dalam lingkaran servis.

2. Saat tester mengatakan ya, tester melakukan keterampilan servis.

3. Masing-masing keterampilan (dengan bentuk keras, tajam dan pelintir).

4. Bola dinyatakan masuk bila :

a) Pelaku dinyatakan tidak melakukan kesalahan.

b) Bola jatuh dalam sasaran yang telah ditentukan (pada angka-angka 1, 2, 3, 4, 5).

c) Bola melambungdinyatakan oleh tester melakukan kesalahan dalam melambung, maka perlakuan pada kesempatan tersebut dapat diulang.

Pengulangan pada kesempatan hanya dapat dilakukan 3 (tiga) kali. Bola pada kesempatan ketiga masih melakukan kesalahan, maka perlakuan dilanjutkan pada kesempatan selanjutnya. 
5. Bola dinyatakan hidup dimana bola tersebut jatuh pada angka $1,2,3,4$ dan

6. Bola yang dinyatakan mati (tidak memenuhi 4) dibeli nilai angka 0, dan dimasukan padapada kolom kesempatan perlakuan dimana bola tersebutdinyatakan mati.

7. Sekor dihitung dari jumlah angka yang didapat dari 10 kesempatan sekor yang dilakukan dengan (1) keras dan tajan (2) pelintir.

Pengumpulan data dalam penelitian ini menggunakan (1) metode observasi, (2) metode dokumentasi dan (3) metode tes perbuatan.

Sesuai dengan rancangan yang digunakan dalam penelitian ini yang dikaitkan dengan tujuan penelitiannya, maka analisis statistik yang digunakan untuk mengetahui apakah ada pengaruh latihan splite terhadap ketepatan sasaran sepak servis dalam permainan sepak takraw, adalah analisis statistik t ( t tes). Adapun bentuk rumus yang digunakan adalah sebagai berikut:

Keterangan : $t=\frac{M_{1}-M_{2}}{\sqrt{\frac{\sum d^{2}}{N(N-1)}}}$

$\mathrm{T}=\mathrm{t}-$ tes

$M 1 \quad$ = Angka rata-rata hasil prestasi angka sepak service sebelum latihan splite

M2 = Angka rata-rata hasil prestasi angka sepak service setelah latihan splite

$\mathrm{N} \quad=$ Jumlah sampel

$\sum d^{2}=$ Jumlah deviasi dari mean perbedaan

$d^{2} \quad=\mathrm{D}-\mathrm{Md}$ sedangkan $\mathrm{Md}=\operatorname{dan} \mathrm{D}=M_{1} M_{2}$. (Netra, $\left.1974: 92\right)$ berikut:

Sedangkan langkah-langkah dalam menguji hipotesis penelitian dilakukan sebagai

1. Merumuskan hipotesis nol

2. Membuat tabel kerja

3. Memasukkan data kedalam rumus

4. Menguji nilai t-tes

5. Menarik kesimpulan.

\section{HASIL}

Berdasarkan hasil penelitian tentang pengaruh latihan splite terhadap ketepatan sasaran sepak service dalam permainan sepak takraw pada team regu putra UNDIKMA Mataram 2020. Berikut data hasil tes pengukuran sepak servis sebelum latihan splite.

\begin{tabular}{|c|c|c|c|c|c|c|c|c|c|c|c|c|c|}
\hline No & Nama & \multicolumn{10}{|c|}{ Skor Sepak Servis } & $\underset{h}{\text { Jumla }}$ & $\begin{array}{c}\text { Nilai } \\
\text { Rata-rata }\end{array}$ \\
\hline 1 & 2 & \multicolumn{10}{|c|}{3} & 4 & 5 \\
\hline & & $\mathrm{I}$ & II & III & IV & $\mathrm{V}$ & $\mathrm{VI}$ & VII & VIII & IX & $\mathrm{X}$ & & \\
\hline 1 & Ade Ardiansyah & 2 & 3 & 0 & 2 & 2 & 1 & 3 & 2 & \begin{tabular}{|c|}
2 \\
\end{tabular} & 1 & 18 & 1,8 \\
\hline 2 & Ari Irawan & 1 & 3 & 2 & 2 & 2 & 1 & 2 & 1 & 3 & 2 & 19 & 1,9 \\
\hline 3 & A. Rahman & 2 & 3 & 3 & 2 & 0 & 1 & 3 & 2 & 2 & 2 & 20 & 2 \\
\hline 4 & Dedi Wahyudi & 2 & 2 & 1 & 0 & 5 & 2 & 1 & 1 & 3 & 2 & 19 & 1,9 \\
\hline 5 & Dikrul Gafilin & 4 & 2 & 2 & 3 & 1 & 0 & 2 & 1 & 2 & 0 & 16 & 1,6 \\
\hline 6 & Lisandi Jaya Putra & 2 & 1 & 1 & 3 & 2 & 4 & 1 & 0 & 5 & 2 & 21 & 2,1 \\
\hline 7 & Memet Ardiansyah & 1 & 2 & 1 & 3 & 2 & 1 & 3 & 2 & 2 & 1 & 18 & 1,8 \\
\hline 8 & Opan Supianto & 3 & 2 & 1 & 0 & 0 & 2 & 2 & 3 & 1 & 3 & 17 & 1,7 \\
\hline 9 & Riyan Febriansyah & 2 & 2 & 3 & 1 & 3 & 2 & 2 & 3 & 1 & 2 & 21 & 2,1 \\
\hline 10 & Ridwansyah & 0 & 2 & 1 & 2 & 0 & 2 & 2 & 1 & 0 & 5 & 15 & 1,5 \\
\hline 11 & Susanto & 4 & 1 & 0 & 5 & 2 & 3 & 2 & 0 & 2 & 2 & 21 & 2,1 \\
\hline 12 & Safrudin & 2 & 2 & 3 & 1 & 2 & 1 & 2 & 1 & 3 & 2 & 19 & 1,9 \\
\hline
\end{tabular}

Adapun data hasil tes pengukuran sepak servis yang peroleh setelah melakakukan program latihan seplite adalah sebagai berikut: 


\begin{tabular}{|c|c|c|c|c|c|c|c|c|c|c|c|c|c|}
\hline No & Nama & \multicolumn{10}{|c|}{ Skor Sepak Servis } & $\begin{array}{c}\text { Jumld } \\
\text { h }\end{array}$ & $\begin{array}{c}\text { Nilai } \\
\text { Rata-rata }\end{array}$ \\
\hline 1 & 2 & \multicolumn{10}{|c|}{3} & \begin{tabular}{|l|}
4 \\
\end{tabular} & 5 \\
\hline & & $\mathrm{I}$ & II & III & IV & $\mathrm{V}$ & $\mathrm{VI}$ & VII & VIII & IX & $\mathrm{X}$ & & \\
\hline 1 & Ade Ardiansyah & 5 & 3 & 4 & 2 & 3 & 2 & 4 & 4 & 5 & 2 & 34 & 3.4 \\
\hline 2 & Ari Irawan & 3 & 5 & 2 & 1 & 3 & 4 & 2 & 2 & 3 & 1 & 26 & 2.6 \\
\hline 3 & A. Rahman & 4 & 2 & 2 & 3 & 1 & 2 & 1 & 1 & 3 & 2 & 21 & 2.1 \\
\hline 4 & Dedi Wahyudi & 1 & 3 & 4 & 2 & 5 & 1 & 2 & 1 & 3 & 2 & 24 & 2.4 \\
\hline 5 & Dikrul Gafilin & 2 & 2 & 4 & 3 & 2 & 3 & 2 & 1 & 0 & 0 & 19 & 1.9 \\
\hline 6 & Lisandi Jaya Putra & 3 & 2 & 0 & 3 & 5 & 2 & 2 & 3 & 1 & 3 & 24 & 2.4 \\
\hline 7 & Memet Ardiansyah & 2 & 4 & 4 & 5 & 2 & 3 & 2 & 0 & 3 & 5 & 30 & 3 \\
\hline 8 & Opan Supianto & 3 & 3 & 2 & 1 & 4 & 4 & 1 & 0 & 5 & 2 & 25 & 2.5 \\
\hline 9 & Riyan Febriansyah & 4 & 0 & 2 & 0 & 5 & 2 & 2 & 3 & 1 & 2 & 21 & 2.1 \\
\hline 10 & Ridwansyah & 3 & 5 & 4 & 3 & 2 & 2 & 2 & 3 & 1 & 3 & 28 & 2.8 \\
\hline 11 & Susanto & 0 & 1 & 4 & 4 & 3 & 3 & 2 & 1 & 0 & 0 & 18 & 1.8 \\
\hline 12 & Safrudin & 5 & 3 & 2 & 3 & 1 & 2 & 2 & 3 & 1 & 3 & 27 & 2.7 \\
\hline
\end{tabular}

\section{Pengujian Hipotesis}

Analisa data tentang pengaruh latihan splite terhadap ketepatan sasaran servis dalam permainan sepak takraw pada team regu putra UNDIKMA Mataram tahun 2020.

1. Merumuskan hipotesis nol (Ho)

Untuk keperluan perhitungan analisis statistik, maka hipotesis alternative (Ha) yang di ajukan pada bab I yang berbunyi: "Ada pengaruh latihan splite terhadap ketepatan sasaran sepak servis dalam permainan sepak takraw pada team rugu putra UNDIKMA Mataram tahun 2020", maka perlu diubah terlebih dahulu kedalam hipotesi nol (Ho) sehingga berbunyi: "Tidak ada pengaruh latihan splite terhadap ketepatan sasaran sepak servis dalam permainan sepak takraw pada team regu putra UNDIKMA Mataram tahun 2020".

2. Membuat tabel kerja

Sesuai dengan rumus yang digunakan, maka tabel kerja yang dibutuhkan adalah tabel kerja untuk menentukan komponen-komponen dalam rumus. Tabel kerja yang dimaksud adalah sebagai berikut:

Tabel untuk menguji hipotesis tentang pengaruh latihan splite terhadap ketepatan servis dalam permainan sepak takraw teambregu putra UNDIKMA Mataram thun 2020.

\begin{tabular}{|c|c|c|c|c|c|}
\hline Sampel & $\mathbf{X}_{\mathbf{1}}$ & $\mathbf{X}_{\mathbf{2}}$ & $\mathbf{D}=\left(\mathbf{X}_{\mathbf{1}}-\mathbf{X}_{\mathbf{2}}\right)$ & $\mathbf{d = D - M d}$ & $\mathbf{d}^{\mathbf{2}}$ \\
\hline $\mathbf{1}$ & $\mathbf{2}$ & $\mathbf{3}$ & $\mathbf{4}$ & $\mathbf{5}$ & $\mathbf{6}$ \\
\hline 1 & 18 & 34 & -16 & $-9,9$ & 98,01 \\
\hline 2 & 19 & 26 & -7 & $-0,9$ & 0,81 \\
\hline 3 & 20 & 21 & -1 & 5,1 & 26,01 \\
\hline 4 & 19 & 24 & -5 & 1,1 & 1,21 \\
\hline 5 & 16 & 19 & -3 & 3,1 & 9,61 \\
\hline 6 & 21 & 24 & -3 & 3,1 & 9,61 \\
\hline 7 & 18 & 30 & -12 & $-5,9$ & 34,81 \\
\hline 8 & 17 & 25 & -8 & $-1,9$ & 3,61 \\
\hline 9 & 21 & 21 & 0 & 6,1 & 37,21 \\
\hline 10 & 15 & 28 & -13 & $-6,9$ & 47,61 \\
\hline 11 & 21 & 18 & 3 & 9,1 & 82,81 \\
\hline 12 & 19 & 27 & -8 & $-1,9$ & 3,61 \\
\hline Jumlah & 224 & 297 & -73 & 0,2 & 354,92 \\
\hline Rata-rata & 18,7 & 27,75 & $-6,1$ & 0,02 & 29,6 \\
\hline
\end{tabular}

Keterangan:

$\mathrm{X}_{1} \quad=$ Nilai ketepatan service sebelum latihan splite

$\mathrm{X}_{2} \quad$ = Nilai ketepatan sepak service setelah latihan splite

$\mathrm{D}=$ Perbedaan antara skor yang berbeda 
D = Perbedaan penyipangan skor.

$\mathrm{d}^{2} \quad=$ Perbedaan skorr perbedaan yang dikuadratkan.

$\mathrm{N}$ = Jumlah sampel yang diteliti.

Maka:

$\mathrm{M}_{1}=\frac{\sum x_{1}}{N}=\frac{224}{12}=18,7$

$\mathrm{M}_{1}=\frac{\sum X_{2}}{N}=\frac{297}{12}=27,75$

$\mathrm{M}_{1}=\frac{\sum D}{N}=\frac{-73}{12}=6,1$

3. Memasukkan data kedalam rumus (analisis data)

Setelah mengetahui nilai X1, X2, D, d², maka langkah selajutnya adalah memasukan nilai kedalam rumus, sedangkan rumus yang dipakai untuk menganalisa data adalah "t-test" dengan rumus pendek.

$$
\begin{aligned}
& t=\sqrt{\frac{M_{1}-M_{2}}{\sqrt{\frac{\sum d^{2}}{N(N-1)}}}} \\
& t=\sqrt{\frac{18,7-27,7}{\sum^{2}}} \\
& t=\sqrt{\frac{-9,05}{N(N-1)}} \\
& t=\sqrt{\frac{354,92}{132}} \\
& t=\frac{-9,05}{1,64} \\
& t=5,518
\end{aligned}
$$

\section{Menguji Nilai t}

Dari hasil analisis data dengan uji perbandingan hasil pengukuran varibel penelitian (Pengaruh Latihan Splite Terhadap Ketepatan Sasaran Sepak Servis), menggunakan tehnik statistik t (uji "t") nilai "t" atau t hitung sebesar -5,518 sedangkan besarnya angka pada tabel nilai "t" dengan huruf signifikasi $5 \%$ dan db $(\mathrm{N}-1)=(12-1)=11$ adalah 2,201.

\section{Menarik Kesimpulan}

Dari hasil uji perbandingan menggunakan $\mathrm{t}$ test menunjukan nilai hitung $\mathrm{t}$ atau $\mathrm{t}$ sebesar $-5,518$ maka berdasarkan taraf signifikasi $5 \%$ dan $\mathrm{db}=\mathrm{N}-1=11$, ternyata besarnya angka batas penolakan hipotesa nol yang menyatakan dalam tabel adalah 2,201. Kenyataan ini menunjukkan bahwa nilai t yang diperoleh dari hasil analisis data sebesar $-5,518$ berada di atas angka batas penolakan hipotesis nol yang besarnya 2,201 (nilai t hitung -5,518>t 2,201) maka dapat disimpulkan bahwa "Ada Pengaruh Latihan Splite Terhadap Ketepatan Sasaran Sepak Servis Dalam Permainan Sepak Takraw Pada Team Regu Putra UNDIKMA MataramTahun 2020".

\section{Pembahasan}

Sesuai dengan kenyataan bahwa rendahnya persentasi permainan sepak takraw yang di alami oleh sebagian atlet bukan hanya di sebabkan karena permainan sepak takraw itu sulit, tetapi juga sebagian di sebabkan oleh berbagai faktor, seperti faktor latihan, kekuatan, kesehatan atau kondisi pada saat itu kurang menguntungkan.

Dengan demikian sangat perlu adanya usaha guna membantu atlet dalam mengatasi masalah yang di alami dengan maksud untuk meningkatkan prestasi dalam cabang olahraga permainan khususnya sepak takraw. Salah satu bentuk bantuan yang bisa diberikan adalah latihan splite guna mendapatkan sepakan yang lebih baik. 
Dari hasil penelitian menunjukkan bahwa atlet yang melakukan latihan splite ternyata dapat meningkatkan prestasi dalam sepak service /sepak mula dibandingkan dengan siswa yang tidak melakukan latihan splite, hal ini karena:

1. Dengan latihan splite akan mendapatkan otot-otot kaki yang kuat dan lebih besar

2. Dengan latihan dapat meningkatkan kesegaran jasmani

3. Dengan latihan splite dapat memelihara kesehatan dan meningkatkan prestasi.

Dengan demikian dapat di tegaskan bahwa atlet yang sering melakukan latihan splite, otot-otot kakinya semakin lentur dan kuat sehingga dapat mengarahkan sepakannya kesasaran dengan baik.

\section{KESIMPULAN}

Berdasarkan hasil penelitian dan analisis data tersebut pada bab IV maka dapat di simpulkan sebagai berikut : "Ada Pengaruh Yang Signifikan Antara Latihan Splite Terhadap Ketepatan Sasaran Sepak Service / Sepak Mula Dalam Permainan Sepak Takraw Pada Team Regu Putra UNDIKMA Mataram Tahun 2020". Ini di sebabkan karena atlet yang melakukan latihan splite secara kontinyu, sepakannya lebih baik di bandingkan dengan atlet yang tidak perna melakukan splite.

\section{DAFTAR PUSTAKA}

Margono, 2004, Metodologi Penelitian Pendidikan, Jakarta :Rineka Cipta.

Moeliono, Anton M. 1988. Kamus Besar Bahasa Indonesia. Jakarta: Balai Pustaka.

Muhammad Sofyan. 2009. Permainan Sepak Takraw. Jakarta : CV Ricardo.

Sumardjo, Jakob. (2001). Seni Pertunjukan Indonesia. Bandung: STSI Press.

Yusuf, Ucup, dkk. 2001. Pembelajaran Permainan Sepak Takraw : Pendekatan Keterampilan Taktis. Jakarta Pusat : Direktorat Jendral Olahraga, Depdiknas. 